\title{
O uso e a toxicomania: considerações com base em Bentham, Marx e Lacan
}

The use and toxicomania: considerations up on Bentham, Marx e Lacan

El uso y la toxicomanía: consideraciones a partir de Bentham, Marx e Lacan

\section{Helena Greco Lisita* \\ Márcia Rosa ${ }^{* *}$}

\begin{abstract}
Resumo
Este trabalho busca investigar, com base na discussão sobre a toxicomania, a noção de uso para a psicanálise. Verifica-se que Lacan vai além do pensamento utilitarista de Bentham quando aponta que o valor de uso de um bem não coincide necessariamente com seu valor de gozo. Lacan introduz a noção de mais de gozar com base na mais-valia de Marx e demonstra que todo discurso está articulado à renúncia, à uma extração de gozo. Denuncia, assim, que o valor de uso de um objeto é particular para cada sujeito e, dessa forma, o gozo tem um valor para o sujeito, uma vez que este o coloca em uso. Esse valor de uso do gozo pode ser demonstrado pelo fato de que o sujeito não declina de fazer uso do gozo, mesmo que esse uso o coloque em risco, fato que a relação com a droga comprova bem.
\end{abstract}

Palavras-chave: Uso. Valor de uso. Valor de gozo. Mais de gozar. Toxicomania.

\begin{abstract}
This paper investigates, from the discussion of drug addiction, the notion of use for psychoanalysis. It appears that Lacan goes beyond the utilitarian thought of Bentham who points out that the value of use does not necessarily coincide with its value of enjoyment. Lacan introduces the notion of over-the-enjoy, from the added value of Marx and demonstrates that all discourse is articulated to an extraction of enjoyment. Denounces thus the usage value of a particular object is for each subject and thus the enjoyment has a value for the subject, since this puts it into use. This usage value of the enjoyment can be demonstrated
\end{abstract}

\footnotetext{
Mestra em Teorias Psicanalíticas pela Universidade Federal de Minas Gerais (UFMG), psicóloga. E-mail: helenagreco@globo.com.

** Pós-doutora em Teoria Psicanalítica pela Universidade Federal do Rio de Janeiro (UFRJ), doutora em Literatura Comparada pela Universidade Federal de Minas Gerais (UFMG), membro da Escola Brasileira de Psicanálise (EBP) e da Associação Mundial de Psicanálise (AMP), professora do Programa de Pós-Graduação em Psicologia da Universidade Federal de Minas Gerais (UFMG), psicóloga, psicanalista. E-mail: márcia.rosa@globo.com.
} 
by the fact that the subject does not decline to make use of enjoyment, even if this use places him at risk, a fact that the relationship with the drug proves all too well.

Keyword: Use. Value of use. Value of enjoyment. Over-the-enjoy. Drug addiction.

\section{Resumen}

Este trabajo investiga, a partir de la discusión sobre toxicomanía, la noción de uso para el psicoanálisis. Se verifica que Lacan va más allá del pensamiento utilitarista de Bentham cuando apunta que el valor de uso de un bien no coincide necesariamente con su valor de gozo. Lacan introduce la noción de más-que-gozar, basándose en la plus-valía de Marx y demuestra que todo discurso se articula para la renuncia, para la negación de gozo. Denuncia por tanto que el valor de uso de un objeto es particular para cada sujeto y, por tanto, el gozo tiene un valor para el sujeto, ya que éste lo pone en uso. Este valor de uso del gozo puede ser demostrado por el hecho de que el sujeto no renuncia a hacer uso del gozo, incluso si este uso lo pone en peligro, hecho que la relación con la droga prueba bien.

Palabras clave: Uso. Valor de uso. Valor de gozo. Más-que-gozar. Toxicomanía.

\section{Introdução}

lugar que a droga ocupa na economia psíquica do sujeito é diversificado. Tal fato nos possibilita pensar nos usos que cada sujeito faz dela, isto é, trata-se de diferentes usos, de diferentes funções da droga, que devem ser consideradas em cada caso clínico (Naparstek, 2005). Em vista disso, cabe investigar a noção de uso. Afinal, o que é possível apreender desse termo? De antemão é possível apontar algumas noções relacionados a ele, tais como "valor de uso" e "valor de gozo", que podem ser relevantes na discussão do uso que cada sujeito faz da droga, assim como em que contexto esse uso se dá.

\section{A noção de uso}

Lacan (1997), ao longo de seu ensino, sobretudo em "O Seminário, livro 7, A Ética na Psicanálise" (1959/1960), ateve-se a estudar a noção de uso, valendo-se, sobretudo, da teoria utilitarista proposta por Jeremy Bentham. 
Bentham (1748-1832) foi um importante filósofo do Direito. O ponto de partida de sua teoria utilitarista encontra-se nos estudos sobre a ciência do Direito, especialmente do Direito natural, que supõe a existência de um contrato original, ao qual o cidadão deve total obediência. Questiona essa doutrina, apontando-lhe duas principais falhas: a impossibilidade de se provar historicamente a existência desse contrato e, ainda que provada sua existência, a possibilidade de se questionar o motivo pelo qual os homens devem obedecer a esse contrato. Para Bentham, a única resposta possível estaria nas vantagens que esse contrato proporciona à sociedade, ou seja, os cidadãos devem obedecer ao Estado na medida em que essa obediência contribui mais para a felicidade geral do que a desobediência.

Vale ressaltar que a ideia de felicidade geral, ou interesse da comunidade em geral, está relacionada ao resultado de um cálculo hedonista, isto é, à soma dos prazeres e dores dos cidadãos. A partir dessa noção, Bentham (1979) propõe a substituição do Direito natural pela teoria da utilidade. Segundo ele, o princípio de utilidade (ou princípio da maior felicidade) reconhece a soberania das duas esferas que regem os homens (a dor e o prazer) e tem como objetivo "construir o edifício da felicidade, através da razão e da lei" (Bentham, 1979, p. 3). O princípio da utilidade tem, portanto, o objetivo de proporcionar "a maior felicidade para o maior número de pessoas" (Bentham, 1979 , p. 5), com base em um conjunto de regras norteadas pela premissa de que todo homem busca a sua própria utilidade e pode alcançá-la do melhor modo.

É possível perceber que Bentham busca desvincular a interpretação da justiça da ideia de excelência do humano. Os atos humanos não têm em si um sentido próprio, só se tornam atos éticos quando referenciados por critérios que definam sua bondade ou maldade. Sobre isso, Miller (1996) acrescenta que o que dá fundamento ao utilitarismo é a convicção de que nada é sem efeito; toda coisa serve, ou não, à outra. A utilidade seria, portanto, o que funda a existência. Ao comentar a teoria benthamiana, o psicanalista afirma que a Natureza, para os utilitaristas, não diz nada, não estabelece nenhuma norma, não impõe nenhum limite. Tem como única função colocar o prazer e a dor à disposição dos mestres para que eles conduzam os homens. Assim, as leis não remetem a discursos pautados pela Natureza ou por Deus. Ao contrário, se desviam disso, elas são concebidas apenas como dispositivos de linguagem capazes de dominar o prazer e a dor em nome do útil.

Entretanto, se o utilitarista abdica de qualquer garantia natural ou divina em nome do útil, cria-se um problema incontornável que diz respeito à origem, ao ex nihilo da lei. Se o útil é a única instância de legitimação, a 
lei só pode ser, então, fruto da enunciação. Ou seja, os direitos e deveres nascem de um ato de linguagem. Ao escrever "A teoria das ficçôes", ${ }^{1}$ Bentham assume esse fato. Se não há natureza legisladora, se o útil é a única instância de legitimação, então a legislação é, do início ao fim, um efeito do discurso. Não se trata, no entanto, de uma tentativa de preenchimento integral do discurso, reduzindo-o a entidades fictícias. Tal como afirma Miller, "Basta lembrar que não há linguagem sem ficçôes. $\mathrm{O}$ utilitarismo não é um nominalismo: não se trata de dissipar as ficçôes, mas de dominá-las, porque as ficções agem" (Miller, 1996, p. 49). A isso acrescenta que "as entidades fictícias mobilizam as entidades reais, as distribuem, as organizam: falar é legislar, isto é, fazer agir coisas que não existem" (Miller, 1996, p. 49). Sendo assim, é possível pensar a teoria das fiç̧ôes como uma teoria da legislação, da linguagem como poder de legislação.

Parece ser justamente isso o que Lacan valoriza na obra de Bentham, tal como ele próprio afirma em $O$ Seminário 7:

Bentham [...] é o homem que aborda a questão no nível do significante. [...] Sua pesquisa consiste não em reduzir a nada todos esses direitos múltiplos, incoerentes, contraditórios, cuja jurisprudência inglesa lhes dá o exemplo, mas pelo contrário, a partir do artifício simbólico desses termos, eles também criadores de textos, e ver o que há em tudo isso que possa servir para alguma coisa [...] (Lacan, 1997, p. 278-279).

Lacan (1997) discute uma passagem do texto de Bentham na qual cita o manto de São Martinho, fazendo uma analogia com a lei e o direito. Trata-se de repartir algo como a capa de São Martinho, ou seja, a capa está disponível para que o maior número possível de indivíduos consiga passar através dela suas cabeças e braços, valendo-se dela como vestimenta: "O homem com direitos começa a se individualizar, uma vez que nesse pano se fazem furos [...], por meio dos quais ele começa efetivamente a se organizar como trajado, isto é, como tendo necessidades que foram satisfeitas" (Lacan, 1997, p. 278). Como afirma Alvarez (2005), esta é a formula utilitarista de Bentham: o pano como "valor de utilidade", mais além da necessidade.

Entretanto, Lacan (1997) vai além do pensamento benthamiano ao questionar a utilização para o gozo. Tal como São Martinho, Bentham centra a questão na partilha, ignorando que, por mais justa que seja essa divisão, há sempre a possibilidade de desejar algo além daquilo que é oferecido. O que

Tal como afirma Miller (1996), a teoria das fiç̧ôes de Bentham não chega a se configurar como uma obra. Trata-se de textos esparsos que, durante muito tempo, não foram considerados importantes, nem mesmo pelos seguidores de Bentham. Alguns desses escritos podem ser encontrados em Bentham's Theory of Ficctions, volume organizado por C. K. Ogden. 
cada um pode fazer com sua capa, indo além de sua utilidade, é o que não está contemplado na teoria benthamiana. Dessa forma, Lacan aponta que o valor de uso de um bem não coincide necessariamente com seu valor de gozo (Alvarez, 2005).

Essa afirmação parece ser preciosa para se pensar a toxicomania. Poderíamos questionar, por exemplo, se o uso da droga na toxicomania é utilitarista. De certa forma, parece que o uso da droga, tem uma função, uma utilidade. Mas não há como desconsiderar que o uso desmedido da droga relaciona-se a um gozo que nada tem a ver com a busca do bem, no sentido utilitarista.

Faz-se aqui necessário ir até as formulaçôes de Lacan dos anos 70, nas quais faz uma retomada das questões abertas em "O Seminário 7". Em "O Seminário, livro 20, Mais, ainda" (1985), Lacan se apoia na noção do usufruto para definir a relação do Direito com o gozo. Segundo ele, essa noção do Direito reúne, em uma só palavra, a diferença que há entre o útil e o gozo: "O usufruto quer dizer que podemos gozar dos nossos meios, mas não devemos enxovalhá-los" (Lacan, 1985, p. 11). Quando se tem usufruto de uma herança, pode-se gozar dela, desde que não a gaste demais. A essência do Direito está no modo de repartir, distribuir, o que diz respeito ao gozo. O gozo, por sua vez, em relação ao útil, é "aquilo que não serve para nada" (Lacan, 1985, p. 11).

O uso da droga aponta para esse aspecto paradoxal da satisfação, ou seja, para o fato de que a satisfação não se relaciona à necessidade, mas sim à pulsão. Nesse sentido, ao passo que a necessidade vincula-se àquilo que é da ordem do útil, a pulsão se apoia "numa utilização de puro gozo" (Santiago, 2001).

\section{Valor de uso e valor de gozo: de Marx a Lacan}

Cabe aqui uma breve incursão no texto de Marx, sobretudo na leitura que Lacan faz da teoria marxista, o que auxiliará na compreensão da noção de mais de gozar, importante para a discussão aqui proposta.

Marx (2004) propõe uma filosofia que, partindo do homem, disponhase a transformar ativamente a própria realidade. Para tanto, parte da análise da sociedade com base em sua estrutura econômica. "O capital" (2004), publicada em 1867, é a obra máxima dessa análise proposta por Marx, na qual constrói uma teoria calcada na noção de que a riqueza, na sociedade capitalista, é baseada no acúmulo de mercadorias. A natureza 
do capital, ou seja, do acúmulo de dinheiro ou de mercadoria, passa a ser o objeto privilegiado em seus estudos.

Marx (2004) emprega a teoria do valor, pela qual o valor de uma mercadoria é determinado pelo tempo de trabalho necessário à sua produção. A mercadoria é vista por ele como algo contraditório que é, ao mesmo tempo, objeto útil (tendo "valor de uso") e objeto de uso para outrem, adquirindo "valor de troca". Embora a utilidade de um objeto determine sua condição de troca, isso não é suficiente para estabelecer seu preço, visto que a utilidade de uma mercadoria está vinculada a critérios subjetivos, generalizáveis, meramente qualitativos. Diante disso, Marx aponta a necessidade de isolar um fator objetivo e mensurável da mercadoria: as horas de trabalho empregadas na produção. $\mathrm{O}$ valor final de um produto seria definido pelo tempo socialmente necessário gasto em sua produção.

Nesse contexto, Marx (2004) enfatiza a importância da força de trabalho no mercado capitalista. $\mathrm{O}$ trabalho passa a ser visto como a verdadeira fonte de riqueza, o único modo de adicionar valor àquilo que é produzido. Com base na noção de que as mercadorias são materializações do trabalho humano, é possível medir a quantidade de trabalho empregado em cada mercadoria e, então, definir seu valor em termos numéricos. O dinheiro é, portanto, apenas a expressão da quantidade de trabalho contida na mercadoria, "a forma necessária de manifestar-se a medida imanente do valor das mercadorias, o tempo de trabalho" (Marx, 2004, p. 121).

O valor pago ao trabalhador é, no entanto, inferior ao real valor de seu trabalho, isto é, ao numero de horas por ele acrescentadas aos produtos. $\mathrm{O}$ salário deverá ser equivalente ao mínimo necessário para a sobrevivência do trabalhador, ao passo que a jornada de trabalho deverá ser a mais longa possível, permitindo a máxima produção. Essa é a única forma capaz de trazer ganho ao capitalista, visto que, se pagasse pela mercadoria final o equivalente aos fatores envolvidos na produção, não obteria ganho qualquer.

Assim, o dono dos meios de produção (o capitalista), ao vender um produto, recebe uma quantia equivalente ao que investiu e, além disso, um excedente, uma mais-valia. O capitalista entrega ao trabalhador parte do valor daquilo que este último produziu, por meio do salário, e se apropria do restante, sob a forma de mais-valia. A noção de mais-valia proposta por Marx pode ser entendida, grosso modo, como a diferença entre os valores do trabalho efetivamente despendido e o trabalho indispensável para a 
sobrevivência, ou seja, o valor a mais cedido pelo trabalhador ao capitalista.

A força de trabalho cria, na realidade, um valor superior ao estipulado inicialmente. Esse trabalho excedente não é pago ao trabalhador e serve para aumentar cada vez mais o capital. Assim, o trabalhador produz uma utilidade, um "valor de uso" não para si, mas para outrem, tornando-se um alienado do próprio trabalho. Desse modo, Marx define o capital como aquilo que garante ao capitalista explorar trabalho, visando ao acúmulo. Isso implica fazer uso do dinheiro a fim de gerar mais dinheiro. Todo o sistema está voltado, portanto, para a mais-valia. O modo como a mais-valia passa a operar no sistema é uma originalidade do capitalismo. A mais-valia ingressa em um sistema infinito: a finalidade é conseguir mais-valia para gerar ainda mais mais-valia. Como afirma Marx, "a circulação de dinheiro como capital tem sua finalidade em si mesma, pois a expansão do valor só existe nesse movimento continuamente renovado. Por isso, o movimento do capital não tem limites" (Marx, 2004, p. 183).

O pensamento de Marx introduz uma nova forma de pensar a exploração no capitalismo, pois invalida a ideia de que o lucro do capitalista advém da exploração sobre o consumidor. Deixa claro que o trabalhador é o verdadeiro explorado, já que a extração da mais-valia não se dá no mercado, mas, sim, em uma etapa anterior, a da produção, por meio da apropriação de parte das horas trabalhadas pelo operário.

Vale ressaltar que a noção de mais-valia não equivale necessariamente à noção de lucro. O preço de uma mercadoria e, consequentemente, o lucro obtido por meio dela estão necessariamente vinculados às contingências do mercado, e, em determinadas situações, o capitalista pode, até mesmo, ter prejuízo na venda de seus produtos. $O$ capitalista, no entanto, não pode deixar de extrair mais-valia, já que é por ela que o funcionamento do sistema se mantém. Embora, na maioria das vezes, a mais-valia possa ser demonstrada por meio do lucro, ela não se reduz a ele (Lustoza, 2009).

Em “O Seminário, livro 16, De um Outro ao outro", Lacan (2008) afirma que a novidade introduzida por Marx é justamente o lugar em que ele situa o trabalho no mercado: "E é isso que permite a Marx demonstrar o que há de inaugural em seu discurso, e que se chama mais-valia" (Lacan, 2008, p. 17). Lacan não valoriza o teor revolucionário do discurso de Marx; ao contrário, tende a desacreditar que a tomada de poder possa produzir qualquer subversão do sujeito capitalista. $\mathrm{O}$ que interessa para ele é a mais-valia, função destacada por Marx exatamente por determinar a predominância do mercado de trabalho. 
Lacan (2008) se vale da noção de mais-valia para elaborar, em um nível homólogo, a noção de mais de gozar. Afirma que a renúncia ao gozo já é conhecida, não sendo nenhuma novidade, assim como não era novidade o trabalho na produção de mercadorias. O que há de novo, no entanto, é existência de um discurso que articula essa renúncia e que evidencia a função do mais de gozar, esta que aparece em decorrência do discurso e é "a essência do discurso analítico" (Lacan, 2008, p. 17).

É preciso supor, no campo do Outro, a existência de um mercado "que totaliza os méritos, os valores e garante a organização das escolhas, das preferências [...]" (Lacan, 2008, p. 17-18). Afirma, ainda, que o discurso, uma vez que implica o sujeito, detém os meios de gozar. O mais de gozar seria, portanto, decorrente da enunciação, produzido pelo discurso, "uma função da renúncia do gozo sob o efeito do discurso" (Lacan, 2008, p. 19). E, a partir disso, dá-se a produção do objeto a. Assim, "o mais de gozar [...] permite isolar a função do objeto a” (Lacan, 2008, p. 19).

Para formular a noção de discurso, Lacan retoma sua afirmação anterior de que "um sujeito é aquilo que pode ser representado por um significante para outro significante"2 (Lacan, 2008, p. 21), representada pelo esquema:

\section{$\frac{\mathrm{S} 1}{\$} \rightarrow \mathrm{S} 2$}

Com base nisso, o objeto a é definido como aquilo que resta dessa operação significante de divisão do sujeito entre dois significantes, ou seja, aquilo que escapa à ordem significante, que é produzido como resíduo da operação significante: "Já não idêntico a si mesmo, daí por diante, o sujeito não goza mais. Perde-se alguma coisa que se chama o mais de gozar" (Lacan, 2008, p. 21). Nesse sentido, o mais de gozar revela o fato de que o significante anula o objeto natural, a satisfação desse objeto. Transforma-o em símbolo, mas, ao mesmo tempo, deixa um resto, que é condição mesma da cadeia significante.

$$
\frac{\mathrm{S} 1}{\$} \rightarrow / / \mathrm{S} 2
$$

Por meio dessa fórmula, Lacan (2008) propõe o "Discurso do Mestre". Segundo ele, esse discurso é também o do inconsciente, uma vez que representa

${ }^{2}$ Lacan propõe essa formulação em “Subversão do sujeito e dialética do desejo” (1960) (Lacan, 1998, p. 807-842). 
a articulação significante do inconsciente com seus efeitos principais e opostos: "O efeito \$ e o efeito a." (Miller, 2008, p. 376). Na linha superior, encontra-se a operação significante mínima $S_{1}-S_{2}$ e, na linha inferior, os efeitos opostos do significante: "o efeito morto, do lado do $\$$ e do outro lado, o produto, o gozo, que ao contrário supõe vida" (Miller, 2008, p. 376).

Lacan (2008) se vale do conceito de repetição proposto por Freud (1996) em "Além do princípio do prazer" (publicado em 1920) para extrair a função do mais de gozar: o discurso pressupóe a perda de um objeto $^{3}$ que o sujeito deverá resgatar, gozo perdido a ser recuperado como mais de gozar. Vale lembrar que, no texto de 1920, Freud reavalia a predominância do principio do prazer no funcionamento do aparelho psíquico. Tal como proposto por ele, esse princípio seria um dos mecanismos de funcionamento psíquico cujo objetivo é manter baixo o nível de excitação do aparelho mental, evitando assim a sensação de desprazer. No entanto, percebe que, se existisse essa dominância, a maioria dos processos mentais teria de ser acompanhada pelo prazer ou conduzir a ele, o que, na prática, não acontece.

O autor do "Seminário 16" afirma que, a partir de "Além do princípio do prazer", fica claro que o princípio do prazer é o princípio da menor tensão que deve ser mantida para a subsistência da vida. Isso demonstra que o gozo transborda o princípio do prazer que, por sua vez, mantém o limite em relação ao gozo. Assim, "a repetição se funda em um retorno do gozo. E o que a esse respeito é propriamente articulado pelo próprio Freud é que, nessa mesma repetição, produz-se algo que é defeito, fracasso" (Lacan, 2008, p. 44). Trata-se da repetição da primeira experiência de satisfação, ou seja, o sujeito está sempre em busca de repeti-la, mas não obtém êxito, não consegue alcançá-la, já que o gozo pleno é impossível. Tem-se, portanto, uma repetição de gozo que implica o reencontro com a falta de gozo (Quinet, 2006).

A partir disso, Lacan (2008) afirma que aquilo que é marcado pela repetição só pode se relacionar ao que se repete em termos de perda e, portanto, "na própria repetição há desperdício de gozo" (Lacan, 2008, p. 44). No lugar dessa perda, introduzida pela repetição, o que aparece é a função do objeto perdido, o objeto a que, nessa vertente, está associado ao desejo.

Nessa vertente de perda, localiza-se a outra face do objeto a como causa do desejo. 


\section{Considerações finais}

Ao retomar a teoria do valor proposta por Marx, Lacan introduz a noção de que todo discurso está articulado à renúncia e, sobretudo, a uma extração de gozo. Assim, o mais de gozar emerge do discurso porque a renúncia ao gozo é um efeito do discurso. Em torno da vertente mais de gozar do desejo, fundamenta-se o essencial sobre a teoria lacaniana a respeito do objeto da pulsão: encontra-se inseparável do gozo como satisfação da pulsão. Dessa forma, reafirma-se a noção de que a droga é um objeto que serve à satisfação, conforme a pulsão pode se satisfazer com um objeto nocivo ao indivíduo. A droga evidencia o paradoxo da satisfação em relação ao objeto: o sujeito se satisfaz a despeito da nocividade tóxica da substância. Ao refletir sobre a relação de dependência que o sujeito estabelece com a droga, deve-se contemplar a dimensão do corpo submetido à ação do discurso e, ao mesmo tempo, inseparável do gozo. Nessa medida, o uso da droga pode ser considerado um modo particular de satisfação, que ultrapassa a dimensão da dependência biológica (Santiago, 2001).

O que se apreende como específico da toxicomania é uma espécie de "curto-circuito" que interrompe a conexão entre o Outro, a fantasia e o gozo fálico. $4 \mathrm{O}$ gozo do toxicômano pode ser compreendido como um gozo que, progressivamente, torna-se mais solitário e que busca unicamente o gozo do próprio corpo (Sinatra, 1994). Tal fato revela, de maneira patética, uma satisfação que não serve para nada, da qual o sujeito não consegue se desvencilhar e que o leva de encontro à morte. Nesse sentido, parece possível afirmar que o toxicômano não pode ser considerado um utilitarista, nem mesmo um capitalista, já que funciona na dimensão de pura perda.

Além disso, é interessante observar que, ao aproximar a noção de mais-valia à de mais de gozar, Lacan (2008) assinala que o conceito marxista encarna o vivo do desconhecido conforme, sob o ângulo da psicanálise, pode-se dizer que existe uma diferença entre o valor natural e permanente do objeto e o valor de libido investido nele. Assim, o valor de uso de um objeto é particular para cada sujeito, ou seja, sujeitos

\footnotetext{
É importante esclarecer que Lacan formaliza a função fálica com base na categoria freudiana do falo, em que prevalece um saber sobre a castração. Embora o termo falo não tenha sido utilizado com frequência por Freud, sendo muitas vezes empregado para se referir ao pênis, o adjetivo fálico ocupa amplo lugar na teoria freudiana da libido, da diferença sexual, sobretudo no que se refere ao complexo de Édipo (Laplanche \& Pontalis, 1992). O gozo fálico, segundo Lacan, é, portanto, aquele que se situa fora do corpo e inclui a fantasia, a partir da crença do sujeito no Outro da castração. A constituição do sujeito é guiada pela sua acomodação ao gozo fálico, e isso envolve o casamento (realizado sob as mais variadas circunstâncias) que o sujeito deve fazer entre o gozo fálico e seu corpo (Miller, 2005).
} 
diversos podem extrair de um mesmo objeto distintas satisfações. Dessa forma, é possível pensar que o gozo tem um valor para o sujeito, uma vez que esse o coloca em uso. E esse valor de uso do gozo pode ser demonstrado por meio do fato de que o sujeito não declina de fazer uso do gozo, mesmo que esse uso o coloque em risco, fato que a relação com a droga comprova bem (Campos, 2008). Assim, o uso da droga ilustra a afirmação de Lacan de que "há outra coisa além do valor de uso, há sua utilização de gozo" (Lacan, 1997, p. 279).

\section{Referências}

Alvarez, E. (2005). Las ficciones de Bentham y el Psicoanálisis. In: Jeremy Bentham. Teoria de las ficciones. (pp. 41-51). Madri: Marcial Pons.

Bentham, J. (1979). Uma introdução aos princípios da moral e da legislação. In: J. Bentham. Os pensadores. (pp. 7-87). São Paulo: Abril Cultural. (Trabalho original publicado em 1989)

Campos, S. (2008). O valor d'objeto. Opção Lacaniana On-line. Recuperado em 6 de dezembro, 2012, de http://www.opcaolacaniana.com.br/antigos/ pdf/artigos/SDCValor.pdf.

Freud, S. (1996). Além do princípio do prazer. In: S. Freud. Edição standard brasileira das obras psicológicas completas de Sigmund Freud (Jayme Salomão, trad., Vol. 18, pp. 17-44). Rio de Janeiro: Imago. (Trabalho original publicado em 1920)

Lacan, J. (1997). A ética da psicanálise . In: J. Lacan. O Seminário (Texto estabelecido por Jacques-Alain Miller. Antonio Quinet, trad., livro 7, pp. 29390. Rio de Janeiro: Jorge Zahar. (Trabalho original publicado em 19591960)

Lacan, J. (2008). De um Outro ao outro. In: J. Lacan. O Seminário (Texto estabelecido por Jacques-Alain Miller. Vera Ribeiro, trad., livro 16, pp.11101. Rio de Janeiro: Jorge Zahar. (Trabalho original publicado em 19681969)

Lacan, J. (1985). Mais, ainda. In: J. Lacan. O Seminário (Texto estabelecido por Jacques-Alain Miller. M. D. Magno, vers. bras., livro 20, pp.10-104. Rio 
de Janeiro: Jorge Zahar. (Trabalho original publicado em 1972-1973)

Lacan, J. (1998). Subversão do sujeito e a dialética do desejo. In: J. Lacan. Escritos. (Vera Ribeiro, trad.). (pp. 807-842). Rio de Janeiro: Jorge Zahar. (Trabalho original publicado em 1960)

Laplanche, J., Pontalis, J-B. (1992). Vocabulário da Psicanálise. São Paulo: Martins Fontes.

Lustoza, Rosane Zétola. (jan./jun., 2009). O discurso capitalista de Max a Lacan: Algumas consequências para o laço social. Revista Ágora, 12 (1), 41 52.

Marx, K. (2004). O capital: crítica da economia política (Reginaldo Sant'anna, trad., livro I, vol. 1). Rio de Janeiro: Civilização Brasileira. (Trabalho original publicado em 1867)

Miller, J. A. (1996). A máquina panóptica de Jeremy Bentham. In: J. Miller. Matemas I. (Sergio Laia, trad., pp. 24-54). Rio de Janeiro: Jorge Zahar.

Miller, J. A. (2005). Silet: os paradoxos da pulsão, de Freud a Lacan. Rio de Janeiro: Jorge Zahar.

Miller, J. A. (2008). El Partenaire-sintoma. Buenos Aires: Paidós.

Naparstek, F. (2005). Introducción a la clínica com toxicomanias y alcoholismo. Buenos Aires: Grama Ediciones.

Quinet, Antonio. (2006). Psicose e laço social: esquizofrenia, paranoia e melancolia. (pp. 9-56). Rio de Janeiro: Jorge Zahar.

Santiago, J. (2001). A droga do toxicômano: uma parceria na era da ciência. Rio de Janeiro: Jorge Zahar.

Sinatra, E. (1994). La existência del goce y la del toxicômano. In: Ernesto Sinatra, Daniel Sillitti \& Mauricio Tarrab (Comp.). Sujeto, goce y modernidade III: de la monotonia a la diversidad. (Vol. 1, pp. 109-120). Buenos Aires: Atuel-TyA. 